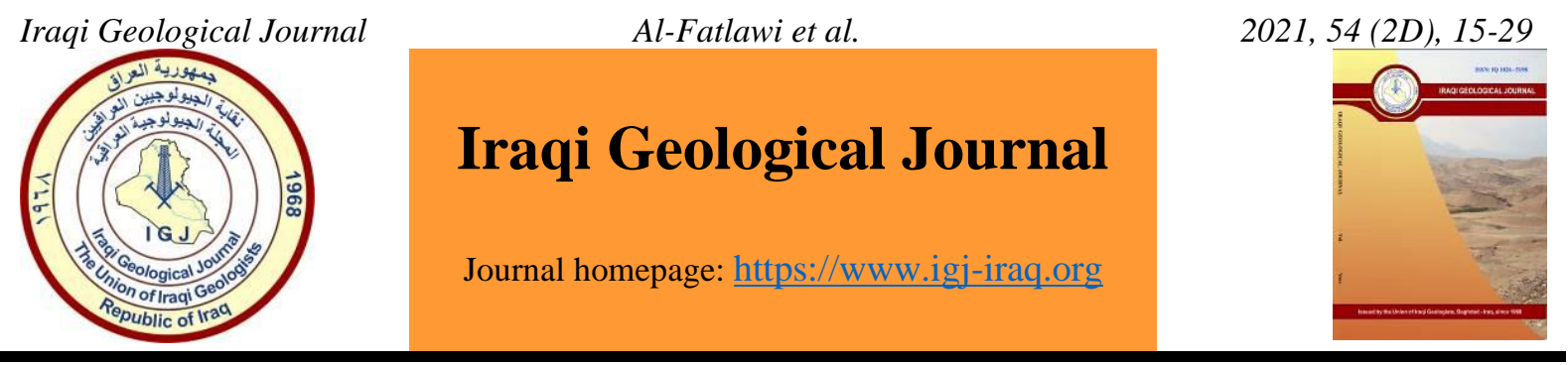

\title{
Estimate Gas Initially in Place of Tight Gas Reservoirs Based on Developed Methodology of Dynamic Material Balance Technique
}

\author{
Omar Al-Fatlawi ${ }^{1,2, *}$, Jeremy Beer ${ }^{2}$ and Mofazzal Hossain ${ }^{2}$ \\ 1 Department of Petroleum Engineering, College of Engineering, University of Baghdad, Iraq \\ 2 Mineral and Chemical Engineering, WA School of Mines, Curtin University, 26 Dick Perry Avenue, 6151 Kensington, \\ Australia \\ * Correspondence: Omar.Al-Fatlawi@coeng.uobaghdad.edu.iq
}

Received: 2 June 2021; Accepted: 22 July 2021; Published: 31 October 2021

\begin{abstract}
With growing global demand for hydrocarbons and decreasing conventional reserves, the gas industry is shifting its focus in the direction of unconventional reservoirs. Tight gas reservoirs have typically been deemed uneconomical due to their low permeability which is understood to be below $0.1 \mathrm{mD}$, requiring advanced drilling techniques and stimulation to enhance hydrocarbons. However, the first step in determining the economic viability of the reservoir is to see how much gas is initially in place. Numerical simulation has been regarded across the industry as the most accurate form of gas estimation, however, is extremely costly and time consuming. The aim of this study is to provide a framework for a simple analytical method to estimate gas. Usually during production three variables are readily accessible: production rate, production time, and pressure-volumetemperature properties. This paper develops an analytical approach derived from the dynamic material balance proposing a new methodology to calculate pseudo time, with an interactive technique. This model encompasses pseudo functions accounting for pressure dependent fluid and rock variables. With the dynamic material balance yielding weak results in the linear flow regimes, an additional methodology derived from the volumetric tank model has been taken into consideration whereby equivalent drainage area is linked to total reservoir area. It has been shown even with short production data this volumetric approach yields accurate results. This proposed methodology has been validated against previous literature and additional cases considered to determine the sensitivity of each of it to reservoir parameters. Finally, it is shown that this method works for both fractured and unfractured wells in tight gas reservoirs, however, it is sensitive to the quantity of data based within the pseudo steady state flow period.
\end{abstract}

Keywords: Gas; Reservoir; Hydrocarbons; Pressure; Permeability

\section{Introduction}

The petroleum industry is quickly depleting conventional resources whilst worldwide demand for hydrocarbons continues to grow (Sadeq, 2018, Al-Fatlawi et al., 2019a, Al-Fatlawi et al., 2019b). To deliver this rising demand, the industry is beginning to develop technologies and techniques to improve economic viability of unconventional reservoirs. Many definitions of tight gas have been proposed in the literature (Hossain et al., 2018, El-Banbi, 1998, Wang et al., 2017), in practice the industry has generally developed the definition proposed by Holditch (2006). To determine if a reservoir is deemed

DOI: $\underline{10.46717 / \text { igj.54.2D.2Ms-2021-10-21 }}$ 
economically viability of a reservoir, the volume of gas initially in place (GIIP) must be known. Currently there are four primary computational methods proposed to estimate GIIP:

- Numerical reservoir simulation

- Material balance

- Volumetric (Tank Model)

- Decline curve analysis

Numerical reservoir simulation is commonly regarded as the most precise form of GIIP estimation (Al-Fatlawi et al., 2019a) however requires a significant data set and extrapolation between wells and reservoir boundaries (Al-Fatlawi, 2018, Dheyauldeen et al., 2021). Tight gas reservoirs (TGRs) modelling can be a complicated expensive mission due to severe heterogeneities and uncertainties tied to reservoir parameters such as porosity and permeability providing a range of variable when history matching. Numerical simulation although precise is a very expensive and time-consuming manner. Decline curve analysis is a simple approach and has been applied for many years (Sun, 2015 and Hazlett et al., 2021), whereby no engineering judgment is made regarding the reservoir simply a decline model is applied to cumulative production-pressure plots which are extrapolated to find GIIP. The fundamental shortcoming is decline curve approaches assume a constant production state for the remainder of the field life, which is impractical in real life. The volumetric approach is simple tank model approach where there is no influence beyond the reservoir boundaries (Al-Fatlawi et al., 2016, Huang et al., 2015). Again, this is a simplest approach, and like reservoir simulation modelling, average reservoir properties must be determined acting as a source of uncertainty.

Three material balance approaches have been proposed in the literature: classic, flowing (Mattar and McNeil, 1998) and dynamic (Mattar and Anderson, 2005) material balance. The classic material balance being restricted to well shut-in (Al-Fatlawi et al., 2016), and the flowing material balance restricted to a constant flow rate. The dynamic material balance removes these restricts and can be used for both a variable and constant flow rate. The advantage of the dynamic material balance is only four components must be known, flow rate, elapse time and fluid gravity. Current literature by Mattar and Anderson (2005) proposes a methodology to apply the dynamic material balance incorporating both pseudo time and pseudo pressures however the methodology presented is incomplete with pseudo time calculated at well flow pressure rather than average reservoir pressure. This study investigates the application of the dynamic material balance and suggests a new methodology to calculate pseudo time improving the accuracy of estimations and reducing computation costs.

\subsection{Material Balance}

The material balance is accepted as the most accurate analytical method to estimate reserves (Mattar and McNeil, 1998, Huang et al., 2015), as the input like decline curve analysis is production data however, reservoir properties, fluid PVT properties, fluid-rock interactions, fluid flows and mass conservation are all taken into consideration.

The material balance can be simply stated as:

$$
\text { Remaining Hydrocarbons = Initial Hydrocarbons }- \text { Produced Hydrocarbons }
$$

This seems to be an uncomplicated equation; however, this is based on the tank model assumption, external contributions and various other properties must be assessed to estimate initial reserves. There are three approaches emphasized in the literature to solve the material balance equation and are reviewed below: 


\subsection{Classic Material Balance}

Classical material balance is one of the primary techniques of reservoir engineering (Pletcher and Engineering, 2002, Okotie and Ikporo, 2019). It states a relationship between cumulative gas production and average reservoir pressure (Singh, 2013). The classic material balance utilizes the well build up test, after a given amount of production the well is shut in for a period to reach the stabilized flow regime (or data extrapolated to reach stabilized flow) to determine average reservoir pressure, this is to be directed at multiple stages in the reservoir's life. For incompressible single-phase fluids, average reservoir pressure versus cumulative production will yield a linear plot. In the case of application to gas reservoirs, the compressibility Z-factor is considered hence, as emphasized by Mattar and McNeil (1998), a P/Z plot versus cumulative production will yield a linear plot. Deviations from this plot can be related to offset drainage or external recharge (Mattar and McNeil, 1998).

Some studies indicate that material balance equation could be inadequate when it is utilized for tight gas reservoir (Holditch, 2006). In other words, the linear relationship of MBE is barely occur for tight gas reservoir (Engler, 2000). The cause for which the linear relationship could not be accomplished is because of two fundamental hypotheses: (1) the pressure variance over the reservoir is relatively small so reservoir can be considered as a single tank; (2) reservoir has a constant drainage area, which are not correct in the case of TGRs. The tight gas reservoir can barely be representative of a single tank model due to considerable variance of pressure in the reservoir. Moreover, the MBE plot is usually based upon stabilized bottom hole pressure, which requires a lengthy and unpractical shut-in interval. Thus, the plot of p/z often provides underestimate of GIIP (Al-Fatlawi et al., 2016, Kuppe et al., 2000). Due to the interpretive error in estimating average reservoir pressure, in particular of TGRs where pressure disturbance propagation is relatively slow and well shut-in for a prolonged period of time is not economically feasible, the classical material balance is not commonly used in TGRs (Payne, 1996, Hagoort and Hoogstra, 1997, Al-Fatlawi et al., 2016).

\subsection{Flowing Material Balance}

The flowing material balance is an improvement on the classic material balance using flowing bottomhole pressure instead of well shut-in pressure. When a reservoir is in the stabilized, pseudo radial flow regime, the pressure decline across the reservoir is constant given a constant production rate, as presented in Fig. 1 with 3 pressure measurements at various times with a constant production rate (Mattar and McNeil, 1998).

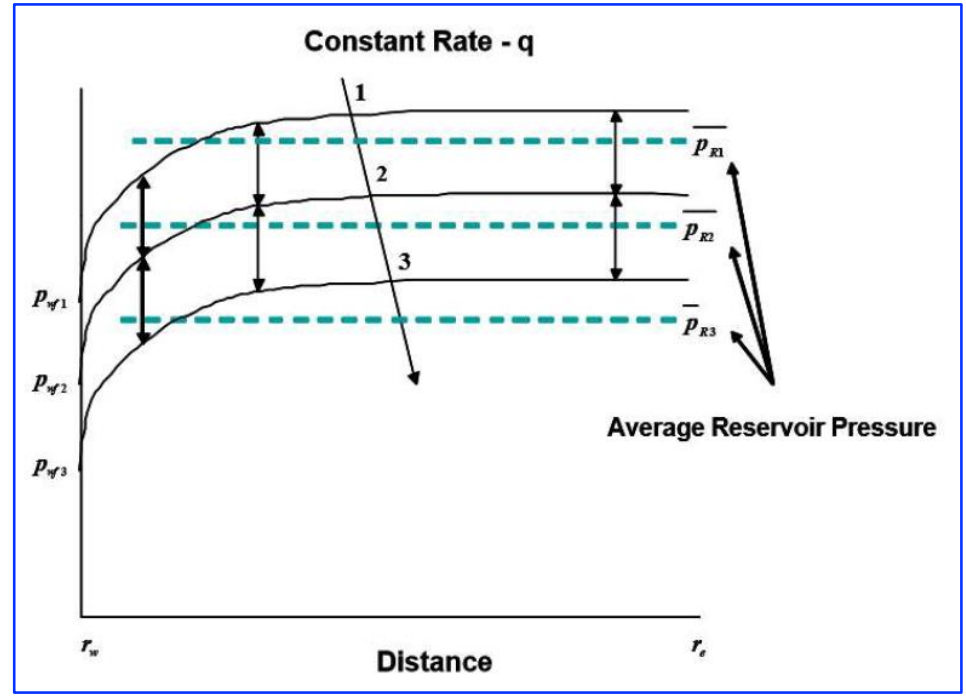

Fig. 1. Reservoir pressure decline pseudo steady state (Mattar and Anderson, 2005) 
It has been emphasized in the literature, pressure response to a constant disturbance is perpendicular to the linear derivation of the classic material balance at any time in stabilized flow regime. This gradient can be translated to include initial reservoir pressure and used to estimate GIIP on a pressure vs cumulative gas production plot (Fig. 2). As the classical approach for gas reservoirs, compressibility Zfactor is considered, plotting $\mathrm{P} / \mathrm{Z}$ versus cumulative production.

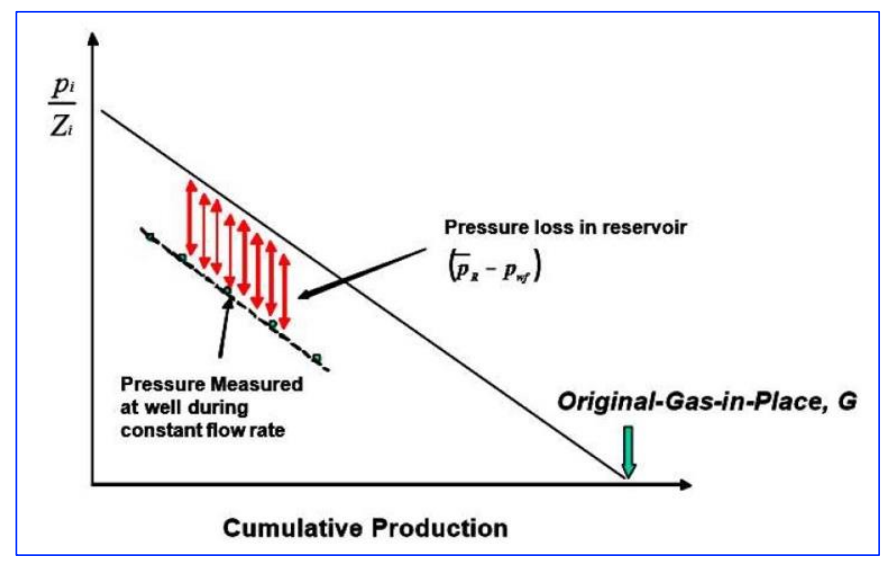

Fig. 2. Flowing material balance (Mattar and Anderson, 2005)

\subsection{Dynamic Material Balance}

The dynamic material balance, is an improvement of the flowing material balance in such a matter that the condition of constant flow rate has been eliminated, as expressed by Mattar and Anderson (2005). It is also emphasized, that Z-factor is not sufficient to account for the variation in PVT properties with pressure for gas production. Hence, pseudo pressure and pseudo time were applied as described by equations 1 and 2 , respectively.

$$
\begin{aligned}
& P_{p}=2 \int \frac{P}{\mu Z} d P \\
& t_{c}=\int \frac{d t}{\mu \overline{c_{g}}}
\end{aligned}
$$

The method proposed by Mattar to calculate GIIP is an iterative approach. It was shown average reservoir pressure could be calculated from variable production rates from equation 3 .

$$
\overline{P_{P R}}=P_{p_{w f}}+b_{p s s} q
$$

Where $b_{p s s}$ is calculated from the intercept of pseudo pressure versus pseudo time plot (Fig. 3).

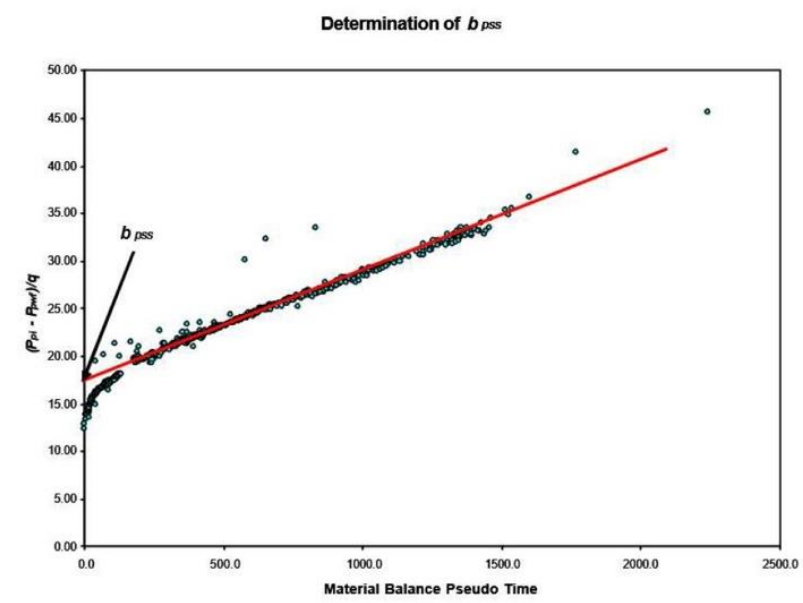

Fig. 3. Calculation of b pss (Mattar and Anderson, 2005) 
Once average reservoir pressure is evaluated $\bar{P} / Z$ vs cumulative production plot can be generated, similar to the FMB and CMB method. This method is presently accepted as the most practical analytical method to calculate GIIP however as highlighted by Feteke (2015). It has been highlighted pseudo time can be difficult to compute without specialized software and assumes a fixed fluid saturation over time and a fixed porosity with pressure. For this reason a new formulation of pseudo time was suggested by Rahman et al. (2006) where pseudo time is a function of pseudo pressure and unifies the effects of time, gas viscosity, gas compressibility, porosity and fluid saturations. This has been achieved through a newly derived definition of total compressibility as shown in equation 4, this can be substituted into equation 2 and Simpson rule or the trapezoidal rule can be applied to compute pseudo time. It is noticed this will generate a truncation error; however, this is minimal in retrospect.

$$
c_{t}=\left(c_{f}+S_{o i} c_{f}+S_{w i} c_{w}+S_{g i} c_{g i}\right)\left(1-c_{g}\left(P_{i}-P\right)\right)+S_{g i}\left(c_{g}-c_{g i}+c_{g} c_{g i}\left(P_{i}-P\right)\right)
$$

This formulation still renders pseudo time difficult to calculate hence it is proposed applying the same bases as Mattar, a simpler iterative approach to compute pseudo time as identified in equation 2. However, it has been noted by Feteke (2015), and previously highlighted, pseudo time is best defined as a function of average reservoir pressure in the region of affluence, because of the pressure disturbance being in the stabilized flow regime, this correlates to average reservoir pressure.

$$
t_{c a}=\frac{G c_{t i}}{q}\left(P_{p_{i}}-\bar{P}_{p}\right)
$$

It should be observed for both the flowing material balance and dynamic material balance, the data must be in the pseudo steady state regime. Moreover, these approaches do not account for pressure dependent permeability or pressure dependent skin factor (Mattar and Anderson, 2005).

\section{Materials and Methods}

As explored in the literature review, estimating GIIP is a crucial component to evaluate economic possibility of a reservoir. Effectively there are three material balance methods to estimate GIIP, these methods stem from the following assumptions:

Table 1. Types of material balance techniques

\begin{tabular}{ll}
\hline Classic Material Balance (CMB) & Shut-in well to generate average reservoir pressure \\
\hline Flowing Material Balance (FMB) & $\begin{array}{l}\text { Constant production, extrapolate and translate decline rate to initial } \\
\text { reservoir pressure }\end{array}$ \\
Dynamic Material Balance (DMB) & Variable production, iterative solution to calculate GIIP \\
\hline
\end{tabular}

To estimate GIIP for all methods production records within the pseudo steady state flow must be analyzed to accurately determine reservoir volume. From these methods, the dynamic material balance approach appreciably has the widest application due to its versatility of variable production rate. Mattar and Anderson (2005) suggested a method to compute GIIP using the dynamic material balance:

- Convert initial reservoir pressure to pseudo pressure $P_{p i}$.

- Convert all flowing pressures to pseudo pressure $P_{p w f}$.

- Assume a value of GIIP.

- Calculate Pseudo Time using Equation 6 (Rahman et al., 2006) . 


$$
t_{c a}=\left(\mu c_{t}\right)_{i} \int \frac{d t}{\overline{\mu c_{g}}}
$$

- Plot $\frac{P p i-P p w f}{q}$ versus pseudo time $\left(t_{c a}\right)$, extending a linear regression line as shown in Fig. 3.

- Calculate average reservoir pressure using equation 3.

- Calculate $P_{\text {res }} / Z$ and plot versus cumulative gas production $G_{p}$ (Fig. 4), as the conventional material balance extend a linear trend line to the $\mathrm{x}$ intercept where GIIP is given.

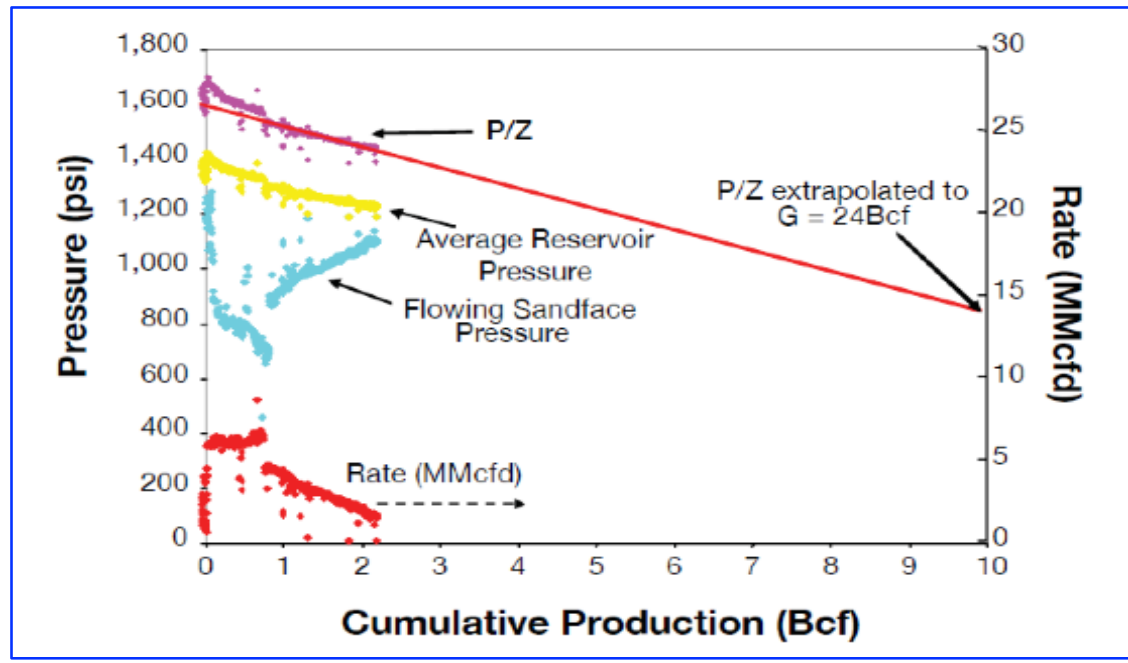

Fig. 4. Extrapolation to find GIIP (Mattar and Anderson, 2005)

- Using the new value of GIIP, repeat steps 5-7 until G converges.

Three issues have been identified when applying this method to estimate GIIP. Firstly, there is no simple method recommended to compute pseudo time. Secondly, it is not apparent as to how the iterative approach delivers an improvement of GIIP estimation. Finally, pseudo steady state flow is identified visually on the $\mathrm{P} / \mathrm{Z}$ and bpss plots generating interpretive uncertainty.Improvements have been proposed to this method as follows, breaking down into PVT analysis and production analysis:

- PVT Analysis

From PVT data, compute pseudo pressure, applying the trapezoidal rule as follow:

$$
\begin{gathered}
P_{p}=2 \int \frac{P}{\mu Z} d P \\
P_{p_{i+1}}=P_{p_{i}}+\left(\left(\frac{P}{\mu Z}\right)_{i}+\left(\frac{P}{(\mu Z)_{i+1}}\right)\right)\left(P_{i+1}-P_{i}\right)
\end{gathered}
$$

Plot pseudo pressure versus pressure and generate an appropriate trendline of the known points.

Generate similar plots for:

- Pressure vs pseudo pressure.

- Z-factor vs pressure.

- Pressure vs P/Z

- Production Data Analysis

- Using Z-factor-pressure correlation and pseudo pressure-pressure conversion trendlines calculate Z-factor and pseudo pressure for each well flow pressures. 
- Estimate GIIP, as a first iteration, the volumetric approach is feasible.

- Calculate cumulative gas production, using the trapezoidal rule as follow:

$$
\begin{gathered}
G_{p}=\int_{0}^{t} q d t \\
G_{p_{i}}=\frac{q_{i}+q_{i+1}}{2} *\left(t_{i}-t_{i-1}\right)+G_{p_{i-1}}
\end{gathered}
$$

Calculate $\frac{\bar{P}}{\bar{Z}}$ as follow:

$$
\frac{\bar{P}}{\bar{Z}}=\frac{P_{i}}{Z_{i}}\left(1-\frac{G_{p}}{G}\right)
$$

- Convert $\frac{\bar{P}}{\bar{Z}}$ to $\bar{P}$ using conversion trendline of $\mathrm{P}$ vs $\mathrm{P} / \mathrm{Z}$, generated in step 1.3.

- Convert $\bar{P}$ to $\overline{P_{p}}$ using pseudo pressure versus pressure trendline, generated in step 1.2.

- Calculate Pseudo Time as follow:

$$
t_{c a}=\frac{G c_{t i}}{q}\left(P_{p i}-\overline{P_{p}}\right)
$$

- Plot $\frac{P_{p i}-P_{P w f}}{q}$ vs $t_{c a}$, like Anderson's method extend a linear line to the y intercept to determine $b_{p s s}$.

- Calculate average pseudo reservoir pressure using equation 3.

- Convert average pseudo pressure to average reservoir pressure, again using the trendline generated in step 1.2.

- Calculate respective Z-factor for average reservoir pressures from trendline of Z-factor vs pressure generate in step 1.3 .

- Plot $\left(\overline{P_{p}}\right) / \mathrm{Z}$ vs Gp extending a linear trend line of the pseudo steady state data to the $\mathrm{x}$ axis to determine GIIP.

- Replace old GIIP with new GIIP in step 2.2 until values converge. These steps of the modified methodology have been further summarized in Fig. 5.

\section{Results}

To validate the proposed methodology, individual cases were run in accordance with Nobakht (2014). Cases 1-4 as shown in Fig. 6. assume a reservoir with multiple unfractured vertical wells. It is appreciated beyond the stimulated reservoir volume (SRV) there is insignificant contribution to production. For cases 1-4 the blue shaded region in figures is identified as the SRV. It is observed in a practical sense, this volume does not correspond to the SRV, but has been selected to assess for comparison with fractured wells are introduced. Cases 5-8 assume a reservoir with multiple fractured wells. For these cases, the SRV is indicated by blue in Fig. 7. This region has a width equivalent to the fracture length, a length equivalent to the no flow boundary between the two vertical wells and a height equivalent to the height of the fracture. It is understood modelling software ECRIN Rubis which is a 3D, 3 phase, multipurpose numerical modeler which sits somewhere between single cell material balance and massive full-field simulation models. It changes neither but does much of the work of both. One can build simple numerical models intuitively with no special training. The geometry can be developed interactively or can be imported from a geomodeler or an alternative simulator. The unstructured Voronoi grid is built automatically to incorporate finer grid cells close to the wells, considers non-Darcy flow and Klinkenberg effect, however, to simplify the model no natural fractures, geomechanical effects, absorption factors or reservoir heterogeneities have been considered. Many 
reservoir studies (Filippov et al., 2017, Al-Fatlawi et al., 2017b, Al-Fatlawi et al., 2017a, Al-Fatlawi, 2018) have utilized ECRIN Rubis to construct the reservoir simulation and those references elaborated the calculations and the purposes of this simulator.

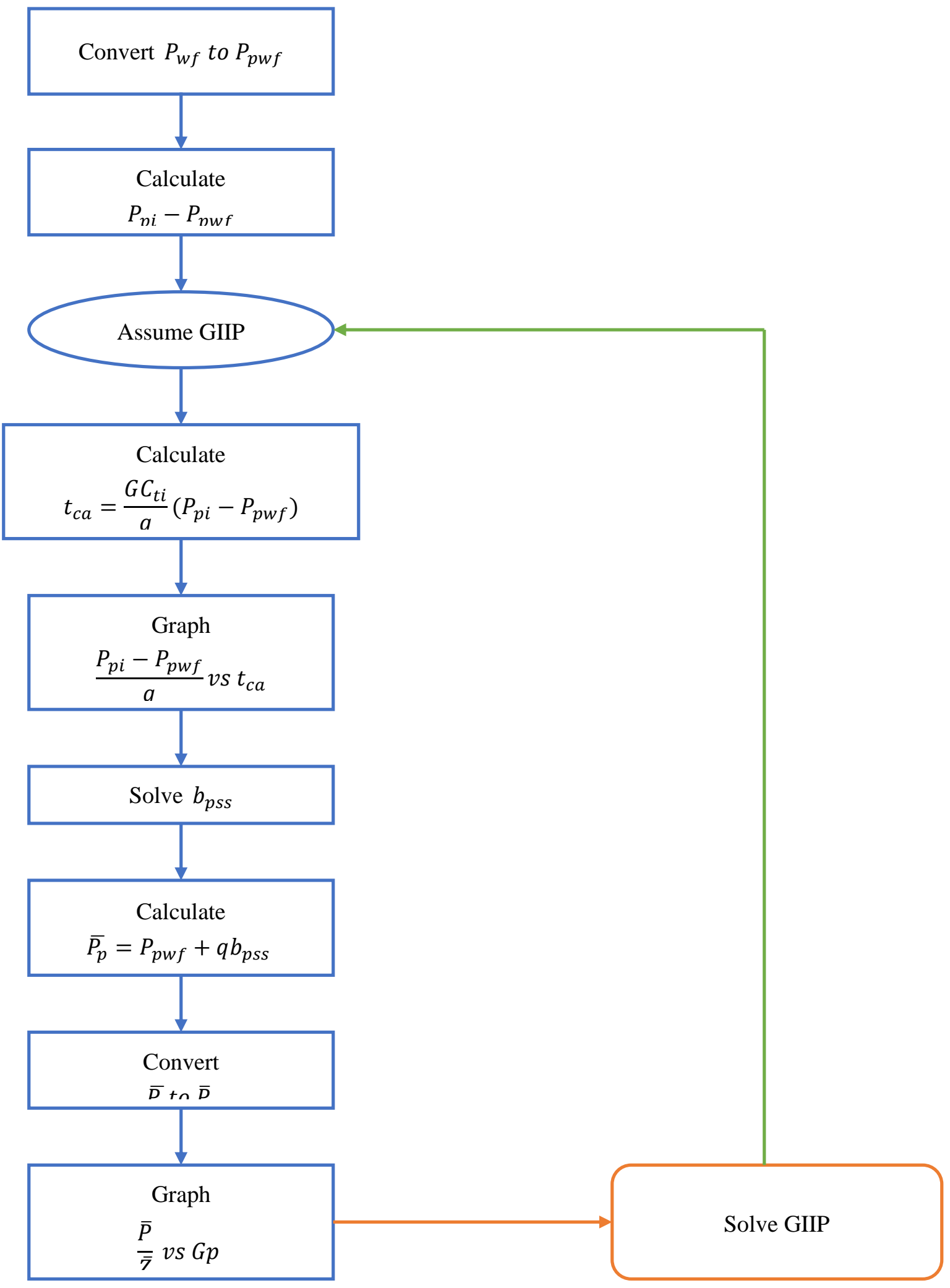

Fig. 5. Iterative flow chart to estimate GIIP 


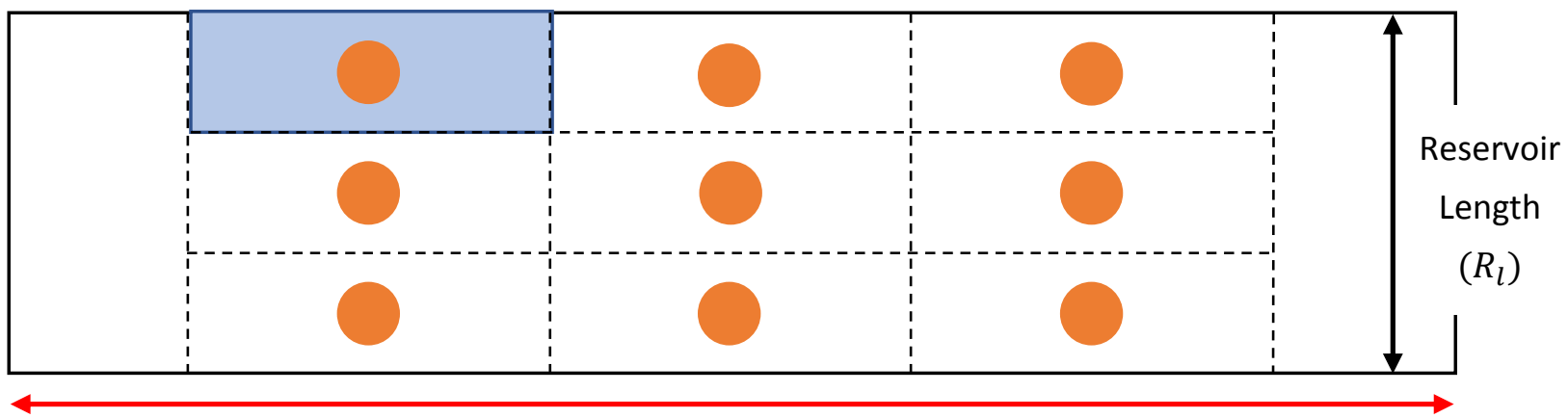

Reservoir Width $\left(R_{z}\right)$

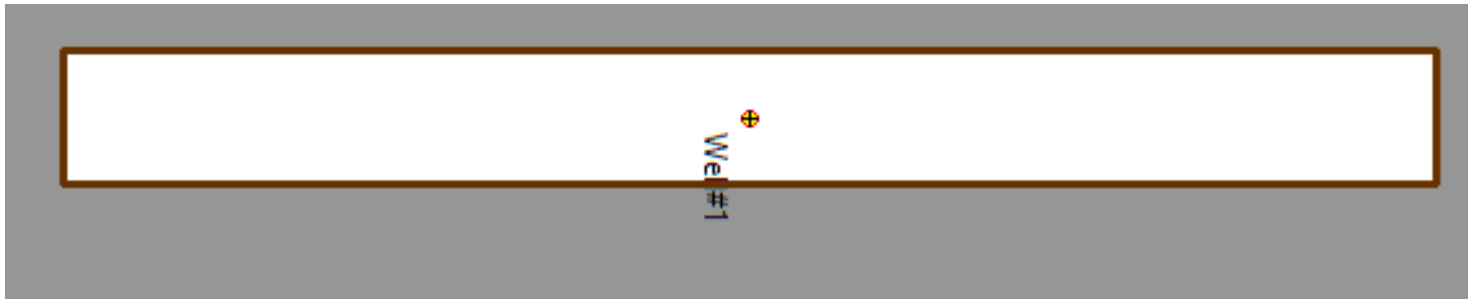

Fig. 6. Simulated Cases 1-4

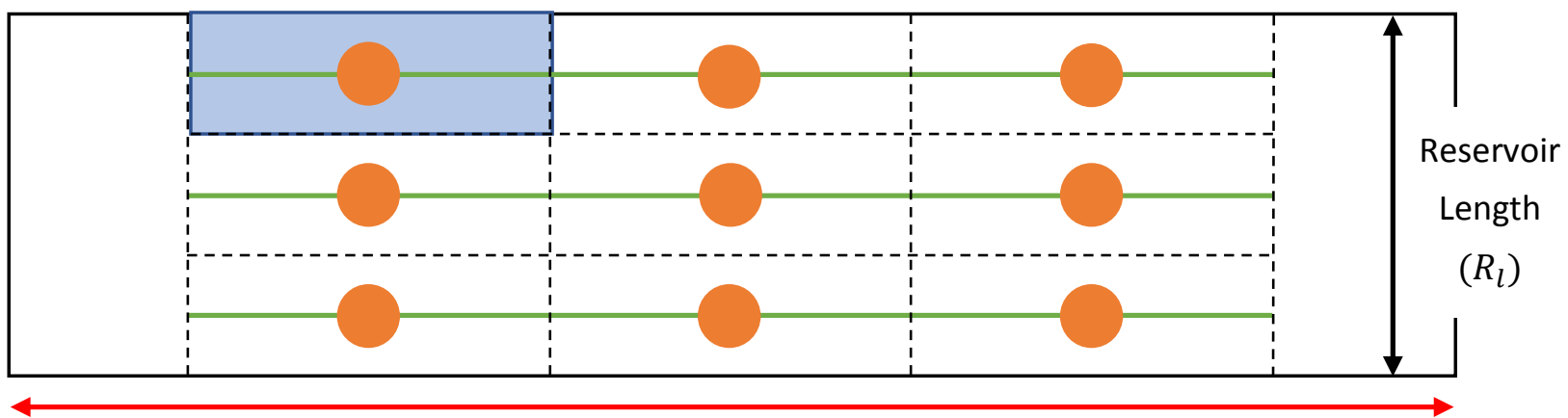

Reservoir Width $\left(R_{Z}\right)$

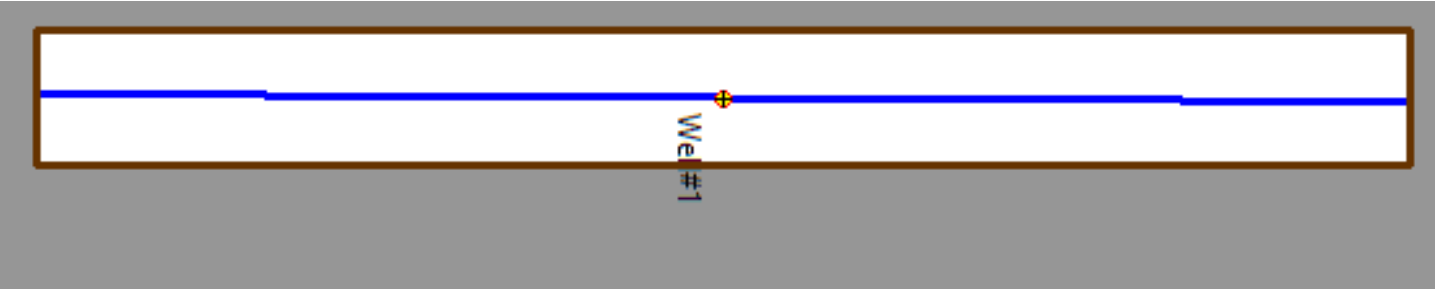

Fig. 7. Stimulated reservoir volume (SRV) Cases 5-8

When simulating, constraints followed a production approach where flowing sand face pressure remains constant whilst production can vary hence only a single pressure pulse enters the system (Fig. 8), Table 2 shows parameters of the 8 cases run and a summary of recorded results, all cases were run for a production period of $5,10,15$ and 20 years. 


\begin{tabular}{|c|c|c|c|c|c|c|c|c|c|c|c|}
\hline \multirow{2}{*}{$\#$} & \multicolumn{3}{|c|}{ t@start } & \multirow{2}{*}{ Mode } & \multicolumn{4}{|c|}{ Target } & \multicolumn{3}{|c|}{ Constraint } \\
\hline & Date & Time & $\mathrm{hr}$ & & Type & Gauge? & Value & Unit & Type & Value & Unit \\
\hline 1 & 01-Jan-2017 & $1: 00: 00 \mathrm{~A}$ & 0 & Produce $\vee$ & $\mathrm{P}(\mathrm{BH})$ & & 3000 & psia & Q Gas (Surf) v & 10000 & Mscfid \\
\hline
\end{tabular}

Fig. 8. Modelling constraints

Table 2. The specifications of the simulated cases of the study

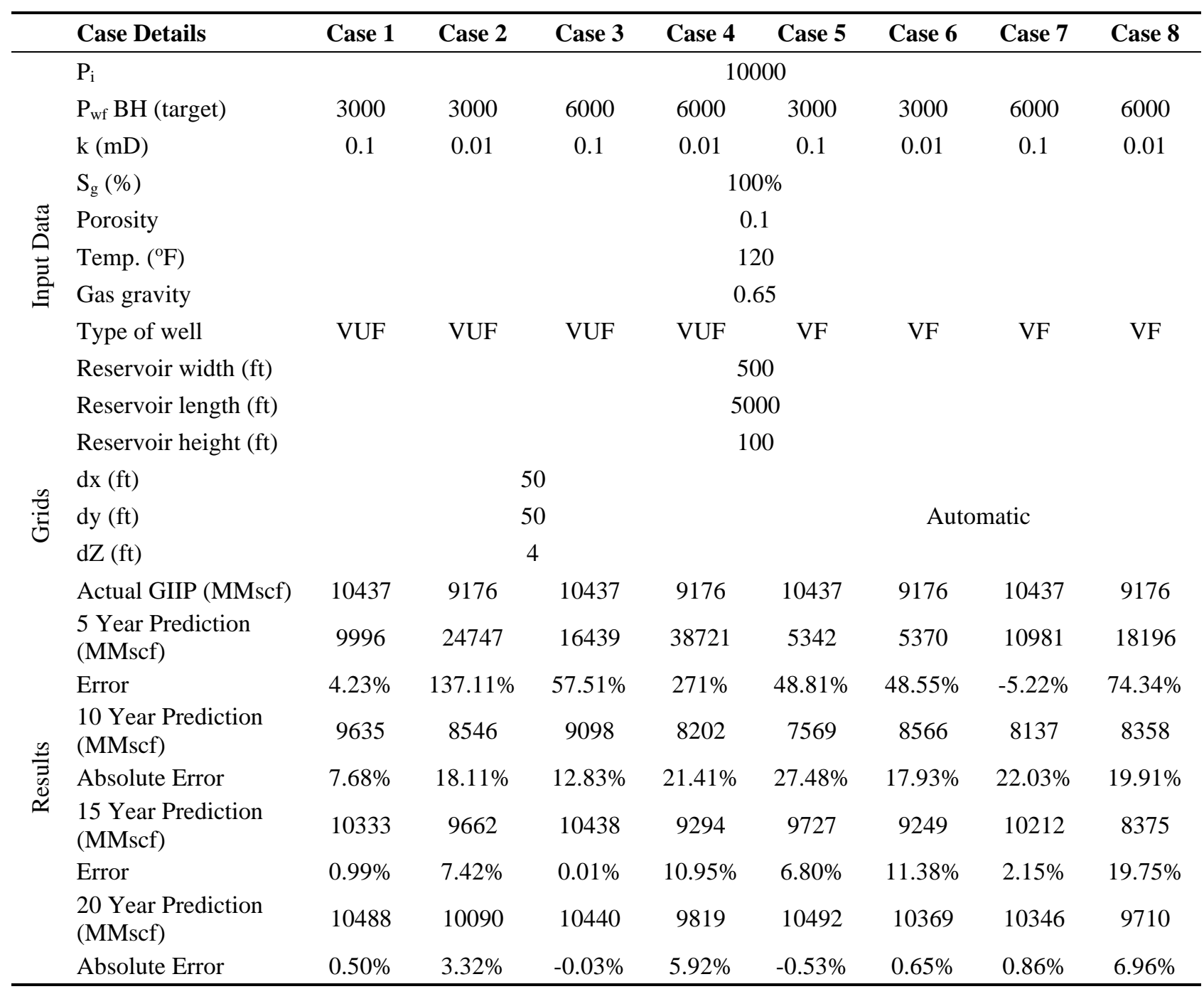

Numerically simulated GIIP is assumed to be the most accurate representation of the reservoir and analytical results were compared to this (Table 3). For cases with a permeability of $0.1 \mathrm{mD}$ the simulated GIIP was $10,437 \mathrm{MMscf}$ and for reservoirs with a permeability of $0.01 \mathrm{mD}$ the simulated GIIP was 9,176MMscf. It is important to note the parameters for this reservoir are not realistic with formation compressibility of $0,100 \%$ saturation of gas and complete lateral homogeneity. These cases have been tested with these simplifying assumptions to confirm the proposed method is able to identify the GIIP. Iterations were run until an absolute error of $0.1 \%$ or less was achieved between the previous and new GIIP. For example, the results of Cases 1 and 5 will be presented in the detail as follow: 


\subsection{Case 1}

For case 1, it was identified pressure stabilized at a time of 6.7 years, indicating the pseudo steady state flow regime has been initiated. This was identified from the GIIP graph, (Fig. 9). The 5-year case had limited data in the pseudo steady state regime, furthermore the length of the transition zone was masked by the two close reservoir boundaries being engaged whilst the further boundaries yet to be reached. For this reason, linear flow data points were considered effectively estimating contacted gasin-place (CGIP). Error for this time is reduced to $4.23 \%$ is not a valid approach and is simply more accurate than the 10-year approach by coincidence, pressure response in the linear flow regime is complicated and this method is not intended for transitional flow interpretation. Evidently, as the time progresses, estimation becomes more accurate.

Table 3. Case 1 - results summary

\begin{tabular}{ccccc}
\hline \multicolumn{5}{c}{ Case 1 Summary } \\
\hline Production period & Calculated GIIP (MMscf) & Absolute Error & Iterations & Depletion \\
5 Years & 9996.11 & $4.23 \%$ & 4 & $25.55 \%$ \\
10 Years & 9635.69 & $7.68 \%$ & 3 & $34.76 \%$ \\
15 Years & 10333.88 & $0.99 \%$ & 5 & $39.54 \%$ \\
20 Years & 10488.78 & $0.50 \%$ & 7 & $42.30 \%$ \\
\hline
\end{tabular}

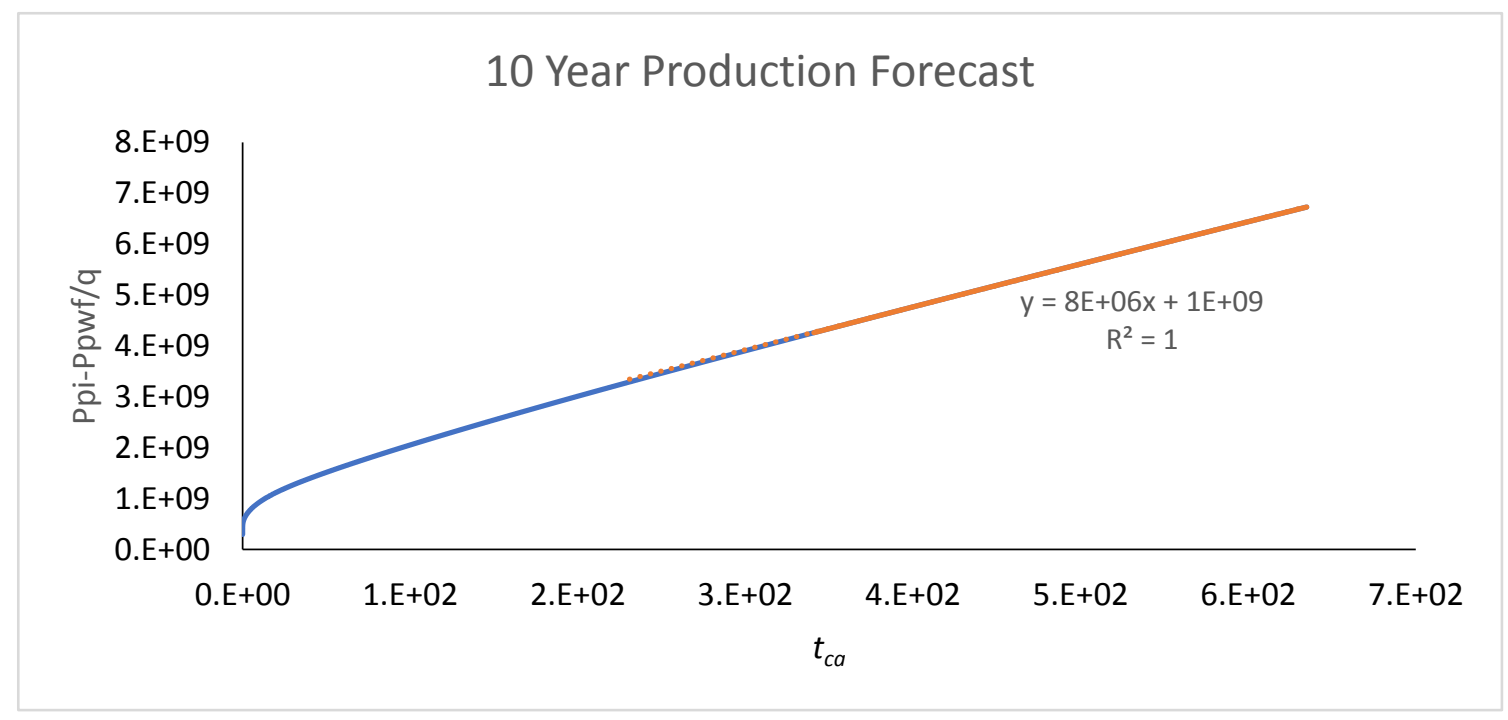

Fig. 9. Identification of stabilized flow

\subsection{Case 8}

Finally, case 8 was similar to that of case 4 with reduced permeability and drawdown. Introducing a hydraulically fractured well nearly doubled depletion from 8.9 to $16.59 \%$, this has significant effect on timestep 5-10 years, where case 4 had limited stabilized flow data. For the 15 and 20-year timesteps there was a considerable volume of data within the stabilized flow regime hence in both cases values converged within $1.3 \%$ of actual GIIP. It is challenging to calculate the drainage area of well in tight gas reservoir as it takes extremely long time for reservoir pressure to reach to the impermeable physical boundary of the reservoir (Al-Fatlawi et al., 2017a). So, the error of the estimation of GIIP using MBE as shown in Table 4 is inversely proportional with the production time because the drainage area extends 
with increasing of the production time. Thus, MBE with the increasing of production time gets more sensible to the reservoir area.

Table 4. Case 8 - results summary

\begin{tabular}{lcccc}
\hline \multicolumn{5}{c}{ Case 8 Summary } \\
\hline Production period & Calculated GIIP (MMscf) & Absolute Error & Iterations & Depletion \\
5 Years & 18196.56 & $98.31 \%$ & 6 & $12.14 \%$ \\
10 Years & 8358.67 & $8.91 \%$ & 3 & $14.86 \%$ \\
15 Years & 9291.56 & $1.26 \%$ & 7 & $16.00 \%$ \\
20 Years & 9244.81 & $0.75 \%$ & 6 & $16.59 \%$ \\
\hline
\end{tabular}

\section{Discussion}

As previously mentioned, numerical simulation has been accepted as the most accurate method to estimate GIIP with analytical results compared with simulated volumes. It is important to note, pseudo time and pseudo pressure consider viscosity and compressibility as a function of pressure, ideal for gas behavior. This step carries significant importance when dealing with gas reservoirs due to the volatility of viscosity and compressibility to pressure. When analyzing single phase oil reservoirs, it is still recommended to consider pseudo functions however their influence on the result is significantly reduced. The proposed method is sensitive to input parameters discussed below:

\subsection{Pressure Drawdown}

As pressure drawdown increases, the accuracy of GIIP estimation improves significantly as can be seen comparing cases 1 and 3 and cases 5 and 7 . This observation applies for both vertical fractured and unfractured well types. This can be explained due to the level of reservoir depletion. A larger downdraw will results in a higher flow rate, as seen in case 1 (10 years) which had produced 3,628.36 MMscf compared to case 3 of 1662.34 MMscf. This can be explained by the analytical productivity index.

\subsection{Well Type}

The proposed method is independent of well type, providing accurate results for all vertical, fractured and unfractured wells. It is however sensitive to the reference point pressure, when analyzing all wells, the reference sand-face pressure is assumed to be at the surface of the reservoir, this reference pressure measurement has been assumed for all well types. It has been noted, vertical fractured wells provide better estimations than unfractured wells with less production data within the stabilized flow regime.

\subsection{Permeability}

Evidently as seen when comparing cases 1 to 2 and 5 to 6 , a decrease in permeability will extend the period of transitional flow, hence more production data is required to estimate GIIP accurately. The radius of investigation is proportional to permeability, hence a decrease in permeability will decrease the radius of investigation at any given time, given that porosity, compressibility, and viscosity remain constant. Although, not highlighted in the cases above, a reduction in porosity, viscosity and compressibility will lead to a greater radius of investigation, hence a shorter transitional flow period and an expected better estimation of GIIP at the time steps conducted in this paper. The proposed method to estimate GIIP can accurately estimate GIIP, given there is sufficient production data in the stabilized flow regime, which is directly related to depletion levels (Fig. 10). 


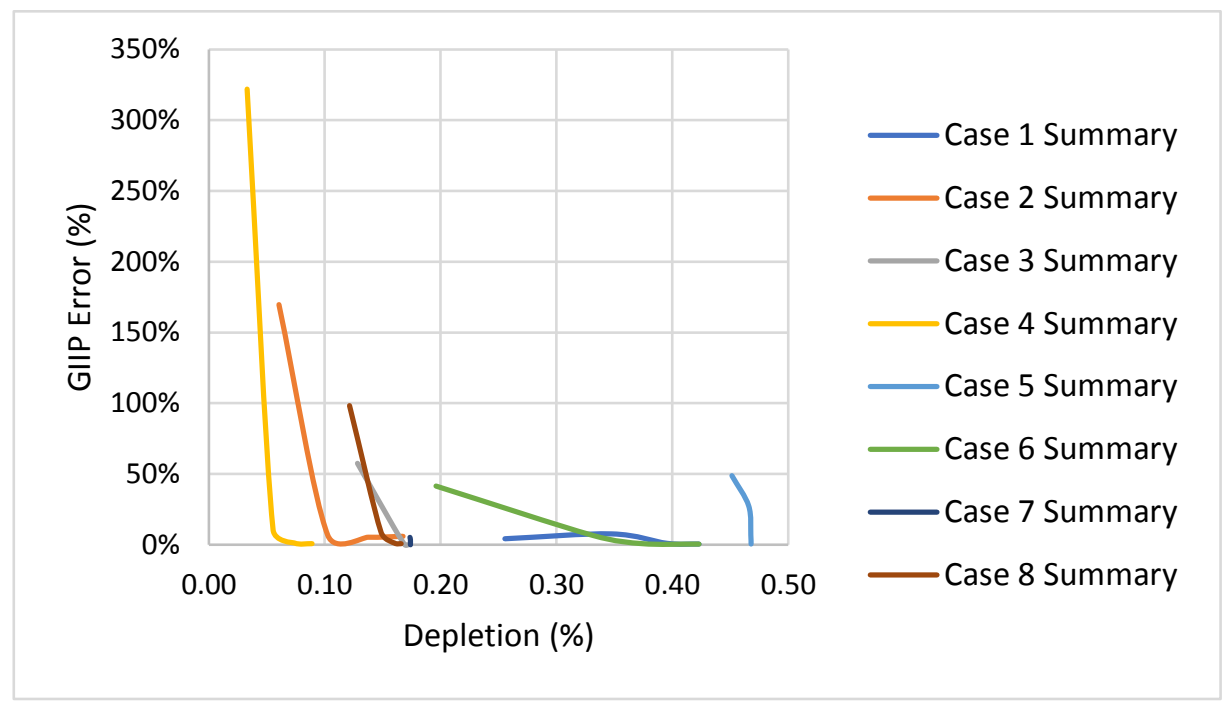

Fig. 10. Absolute error versus level of depletion

\section{Conclusions and Recommendations}

- The proposed method can be programmed using a programming language, so it overcomes the need to a commercial simulator to estimate GIIP for TGRs.

- The proposed method requires data much less than for a commercial simulator.

- Greater level of reservoir depletion and stabilized flow data points delivers a more accurate GIIP estimation for TGRs, due to more data points within stabilized flow regime.

- Proposed method applies for both unfractured and fractured wells in TGRs.

- Further work to improve determination of the commencement of stabilized flow regimes, validate for horizontal wells and once completed a field example conducted.

\section{Nomenclature}

$\overline{c_{g}}$ gas compressibility at average reservoir pressure, $\mathrm{psi}-1$

$p$ pressure, $\mathrm{psi}$

$P_{i} \quad$ initial pressure, $\mathrm{psi}$

$P_{p} \quad$ pseudopressure, $\mathrm{psi} 2 / \mathrm{cp}$

$\overline{P_{p}} \quad$ pseudopressure at average pressure, $\mathrm{psi} 2 / \mathrm{cp}$

$P_{p_{i}}$ pseudopressure at initial reservoir pressure, $\mathrm{psi} 2 / \mathrm{cp}$

$G$ gas initial in place, Mscf

$G_{p}$ cumulative gas production, MMscf

$\overline{P_{P R}}$ pseudopressure at average reservoir pressure, $\mathrm{psi} 2 / \mathrm{cp}$

$P_{p_{w f}}$ pseudopressure at flowing bottomhole pressure, $\mathrm{psi} 2 / \mathrm{cp}$

$q$ gas flow rate, $\mathrm{Mscf} / \mathrm{D}$

$t$ time, days

$t_{c a}$ material balance pseudo-time for gas $=\left(\mu c_{t}\right)_{i} \int \frac{d t}{\overline{\mu c_{g}}}$

$t_{c} \quad$ material balance pseudo-time for gas $=\int \frac{d t}{\mu \overline{c_{g}}}$

$z \quad$ gas deviation factor

$\mu$ gas viscosity, $\mathrm{cp}$ 


\section{Acknowledgements}

The authors would like to thank KAPPA Engineering for providing the license of their software. The authors are very grateful to the Editor in Chief Prof. Dr. Salih M. Awadh, the Secretary of Journal Mr. Samir R. Hijab. and the Technical Editors for their great efforts and valuable comments.

\section{References}

Al-Fatlawi, O., Hossain, M. \& Essa, A., 2019a. Optimization of fracture parameters for hydraulic fractured horizontal well in a heterogeneous tight reservoir: an equivalent homogeneous modelling approach. SPE Kuwait Oil \& Gas Show and Conference, 2019a. Society of Petroleum Engineers.

Al-Fatlawi, O., Hossain, M., Patel, N. \& Kabir, A., 2019b. Evaluation of the Potentials for Adapting the Multistage Hydraulic Fracturing Technology in Tight Carbonate Reservoir. SPE Middle East Oil and Gas Show and Conference.

Al-Fatlawi, O., Hossain, M. M. \& Saeedi, A., 2017a. A new practical method for predicting equivalent drainage area of well in tight gas reservoirs. SPE Europec featured at 79th EAGE Conference and Exhibition, OnePetro.

Al-Fatlawi, O., Mofazzal, M. H., Hicks, S. \& Saeedi, A., 2016. Developed material balance approach for estimating gas initially in place and ultimate recovery for tight gas reservoirs. Abu Dhabi International Petroleum Exhibition \& Conference, Society of Petroleum Engineers.

Al-Fatlawi, O., Vimal Roy, A. R., Hossain, M. M. \& Kabir, A. H., 2017b. Optimization of Infill Drilling in Whicher Range Field in Australia. SPE Kingdom of Saudi Arabia Annual Technical Symposium and Exhibition.

Al-Fatlawi, O. F. 2018. Numerical simulation for the reserve estimation and production optimization from tight gas reservoirs. Curtin University of Technology.

Dheyauldeen, A., Al-Fatlawi, O. \& Hossain, M. M., 2021. Incremental and acceleration production estimation and their effect on optimization of well infill locations in tight gas reservoirs. Journal of Petroleum Exploration Production Technology, 2449-2480.

El-Banbi, A. H. 1998. Analysis of tight gas well performance, Texas A\&M University.

Engler, T. W. A new approach to gas material balance in tight gas reservoirs. SPE Annual Technical Conference and Exhibition, 2000. OnePetro.

Filippov, D. D., Kudryashov, I. Y., Maksimov, D. Y., Mitrushkin, D. A., Vasekin, B. V. \& Roshchektaev, A. P. 2017. Reservoir modeling of complex structure reservoirs on dynamic adaptive $3 \mathrm{~d}$ pebi-grid. SPE Russian Petroleum Technology Conference, 2017.

Hagoort, J. \& Hoogstra, R., 1997. Numerical solution of the material balance equations of compartmented gas reservoirs. SPE Asia Pacific oil and gas conference and exhibition, OnePetro.

Hazlett, R. D., Farooq, U. \& Babu, D. K. J. S. J. A., 2021. Complement to decline curve analysis. 1-11.

Holditch, S. A., 2006. Tight gas sands. Journal of Petroleum Technology, 58, 86-93.

Hossain, M. M., Al-Fatlawi, O., Brown, D. \& Ajeel, M., 2018. Numerical approach for the prediction of formation and hydraulic fracture properties considering elliptical flow regime in tight gas reservoirs. Offshore Technology Conference Asia, Offshore Technology Conference.

Huang, Q.-H., Chen, C., Yin, L., Liu, T. \& Fang, T., 2015. Application of material balance equations of multicompartment gas reservoirs in yc gas reservoir. 6th International Conference on Manufacturing Science and Engineering, Atlantis Press, 554-569.

Kuppe, F., Chugh, S. \& Connell, P., 2000. Material balance for multi-layered, commingled, tight gas reservoirs. SPE/CERI gas technology symposium, OnePetro.

Mattar, L. \& Anderson, D., 2005. Dynamic material balance (oil or gas-in-place without shut-ins). Canadian International Petroleum Conference, Petroleum Society of Canada.

Mattar, L. \& Mcneil, R. J. J. O. C. P. T. 1998. The flowing gas material balance, 37.

Nobakht, M. 2014. New and Improved Methods for Performing Rate-Transient Analysis of Tight/Shale Gas Reservoirs. Doctoral University of Calgary.

Okotie, S. \& Ikporo, B., 2019. Linear Form of Material Balance Equation. Reservoir Engineering. Springer. 
Payne, D. A. J. S. R. E. 1996. Material balance calculations in tight-gas reservoirs: The pitfalls of p/z plots and a more accurate technique, 11, 260-267.

Pletcher, J. L., 2002. Improvements to reservoir material-balance methods." SPE Reservoir Evaluation \& Engineering 5.01, 49-59.

Rahman, N. A., Mattar, L. \& Zaoral, K. 2006. A new method for computing pseudo-time for real gas flow using the material balance equation. Journal of Canadian Petroleum Technology, 45.

Sadeq, D. J. 2018. Gas Hydrates Investigation: Flow Assurance for Gas Production and Effects on Hydrate-bearing Sediments. Curtin University.

Singh, V. K., 2013. Overview of material balance equation (MBE) in shale gas \& non-conventional reservoir. SPE Middle East Oil and Gas Show and Conference, Society of Petroleum Engineers.

Sun, H. 2015. Advanced production decline analysis and application, Gulf professional publishing.

Wang, L., Wang, S., Zhang, R., Wang, C., Xiong, Y., Zheng, X., Li, S., Jin, K., Rui, Z. J. J. O. N. G. S., 2017. Review of multi-scale and multi-physical simulation technologies for shale and tight gas reservoirs. 37 , 560-578. 